\title{
Influence of shrinkage porosity on fatigue performance of iron castings and life estimation method
}

\author{
${ }^{*}$ Wei Liu ${ }^{1}$, Wei-hao Zhai ${ }^{1}$, and Jun-feng Zhao ${ }^{2}$ \\ 1. School of Mechanics, Civil Eng. \& Architecture, Northwestern Polytechnical University, Xi'an 710129, China \\ 2. China Helicopter Research and Development Institute, Jingdezhen 333000, China
}

\begin{abstract}
Shrinkage porosity exists more or less in heavy castings, and it plays an important role in the fatigue behavior of cast materials. In this study, fatigue tests were carried out on the QT400-18 cast iron specimens containing random degrees of shrinkage porosity defect. Experimental results showed that the order of magnitude of life scattered from $10^{3}$ to $10^{6}$ cycles when the shrinkage percentage ranged from $0.67 \%$ to $5.91 \%$. SEM analyses were carried out on the shrinkage porosity region. The inter-granular discontinuous, micro cracks and inclusions interfered with the fatigue sliding or hindering process. The slip in shrinkage porosity region was not as orderly as the ordinary continuous medium. The shrinkage porosity area on fracture surface (SPAFS) and alternating stress intensity factor (ASIF) were applied to evaluate the tendency of residual life distribution; their relationship was fitted by negative exponent functions. Based on the intermediate variable of ASIF, a fatigue life prediction model of nodular cast iron containing shrinkage porosity defects was established. The modeling prediction was in agreement with the experimental results.
\end{abstract}

Key words: shrinkage porosity; iron castings; fatigue life; alternating stress intensity factor; equivalent initial crack CLC numbers: TG146.23

Document code: $A$

Article ID: 1672-6421(2016)01-047-07

$\mathrm{Q}$ T400-18 large iron castings are widely used in a ship's diesel engines, crankshaft, etc. However, shrinkage porosity defects often exist in heavy section iron castings if the casting process is not well controlled or the casting method is not well designed. It is very difficult to get a perfect casting, especially a heavy section casting ${ }^{[1,2]}$. As large castings have concentrated large labor costs during fabrication, enormous waste would be incurred if the large casting product was declared worthless. For some applications, a certain degree of shrinkage defect is allowable to exist in selected critical locations, a few percentage of shrinkage porosity in large casting is tolerated sometimes, but shrinkage porosity introduces uncertainty into the material's mechanical performance ${ }^{[3,4]}$, which becomes a potential threat. If accidents due to shrinkage porosity defect occurred in large casting equipment, subsequent

*Wei Liu

Male, born in 1981, Ph. D., Associate Professor. His research focus is mainly on the influence of shrinkage porosity on the mechanical properties of castings and simulation methods.

E-mail: liuwei@nwpu.edu.cn

Received: 2015-07-06; long-period troubleshooting and expensive maintenance might be also a problem. Therefore, for the purposes of design specifications and quality control, quantifying the influence of shrinkage porosity defect on fatigue performance is crucial.

As an important type of casting defect, shrinkage porosity has received wide attention and research. Because of its unsound morphology, shrinkage porosity reduces the effective section and induces stress concentrations. This deleterious effect has been widely recognized. In order to obtain quantitative model, shrinkage porosity is usually deemed as a type of pore/ hole defect, some parameters, such as void volume fraction, maximal/mean pore size, defect areas, were used to characterize the effects on strength and stiffness. Many empirical formulas for the loss of stiffness and ductility, stress concentrations, or stress redistribution were established ${ }^{[3-6]}$. Tijani ${ }^{[2]}$, Hardin ${ }^{[7]}$, and Wan et al. ${ }^{[8]}$, applied radiographic imaging to get a three-dimensional morphology of shrinkage porosity. This allowed the reconstruction of a more real porosity model for finiteelement tensile analysis, and the ductile fracture and plastic behavior caused by shrinkage porosity were well simulated. 
On the aspects of fatigue performance, many investigations have shown that the shrinkage porosity defect greatly affects fatigue resistance, not only during the fatigue crack propagation process but also in the initiation period ${ }^{[1,2,9,10]}$. The volume fraction or size of shrinkage porosity defect was often used as a characteristic parameter. Some investigations pointed out that there was a critical pore size, and shrinkage porosity was tolerable if its maximal pore size was smaller than the critical size ${ }^{[11-14]}$. Unfortunately, this critical size was not uniform (the value ranged from $25 \mu \mathrm{m}$ to $100 \mu \mathrm{m}$ ) because of different materials and experimental conditions. Another reason was that the shapes, positions and micro-morphologies etc. of shrinkage porosity in different specimens were essentially random, the porosity percentage or defect size/pore size was not the only determining factor. For example, the life of surface defect (porosity exposed on the surface of structure) was one order of magnitude less than that of internal defect ${ }^{[15-18]}$. Mo et al. ${ }^{[19]}$ and $\mathrm{Xu}$ et al. ${ }^{[20]}$ pointed out that the fatigue crack initiation and propagation were affected by many factors, such as the position, shape and maximal pore size. Wang et al. ${ }^{[11]}$ and Cai et al. ${ }^{[21]}$ examined other factors, such as the secondary dendrite arm spacing (SDAS) and eutectic particle. Murakami ${ }^{[22]}$ proposed the stress intensity factor (SIF) of porosity to evaluate the combined influence of multiple-factors. The equivalent model should be modified according to experimental results of different casting materials ${ }^{[23,24]}$. However, it is still insufficient for the assessment of castings containing shrinkage porosity; more experimental data and effective methods should be provided for engineering application.

This study is aimed at quantifying the influence of shrinkage porosity on fatigue performance and establishing an effective method to evaluate the residual life of shrinkage porosity defect casting. The work will be helpful in determining a safety criterion for heavy iron castings with unavoidable shrinkage porosity.

\section{Experimental procedures}

\subsection{Test material and specimens}

The material used in this study was a type of nodular cast iron material, named as QT400-18(ISO: 400-18). QT400-18 was often made for cylinder ingot, engine block or crankshaft, etc. in heavy diesel engines. Shrinkage porosity was prefabricated in the center of QT400-18 cast iron ingots. Firstly, a cubic casting mold (as shown in Fig. 1) was used to provide a range of solidification times. Random shrinkage porosity was formed at the hot spots within the casting ingot, the produced wedgeshaped casting ingots were approximately $180 \mathrm{~mm}$ in height and $300 \mathrm{~mm}$ in length. The ingots were cut into a number of pieces (thickness: $5 \mathrm{~mm}$ ) from the transverse direction, and the defect was located in the center of each piece. Each piece then was machined into the fatigue test specimen, as shown in Fig. 2 (unit: $\mathrm{mm}$ ). Other details of the specimen preparations conformed to standard GB3075-2008. In this way, a series of specimens

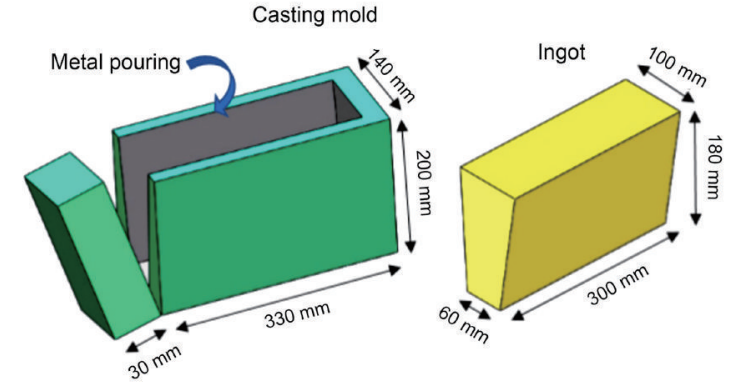

Fig. 1: Schematic of casting mold and wedge ingot

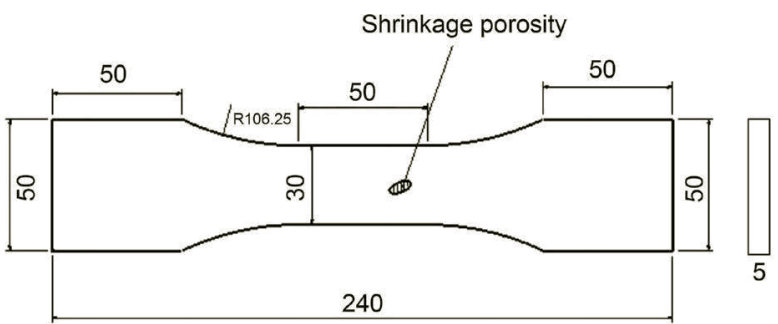

Fig. 2: Dimensions of fatigue specimen containing shrinkage porosity $(\mathrm{mm})$

containing random shrinkage porosity in the gauge section were prepared.

There was no fault detected in one of the above specimens after X-ray detection. The specimen was considered a defectfree specimen. Tensile performance of the defect-free specimen was obtained by monotonic tensile test; the test was carried out using an Instron-8802 servo hydraulic universal machine. The loading rate was $2 \mathrm{~mm} \cdot \mathrm{min}^{-1}$. The whole strain data of the gauge section (the gauge length was $50 \mathrm{~mm}$ ) were obtained by an MTS extensometer. The stress-strain response of the defect-free material under monotonic tensile loading is shown in Fig. 3. Here, the stress was defined as applied loading divided by original cross-sectional area of specimen.

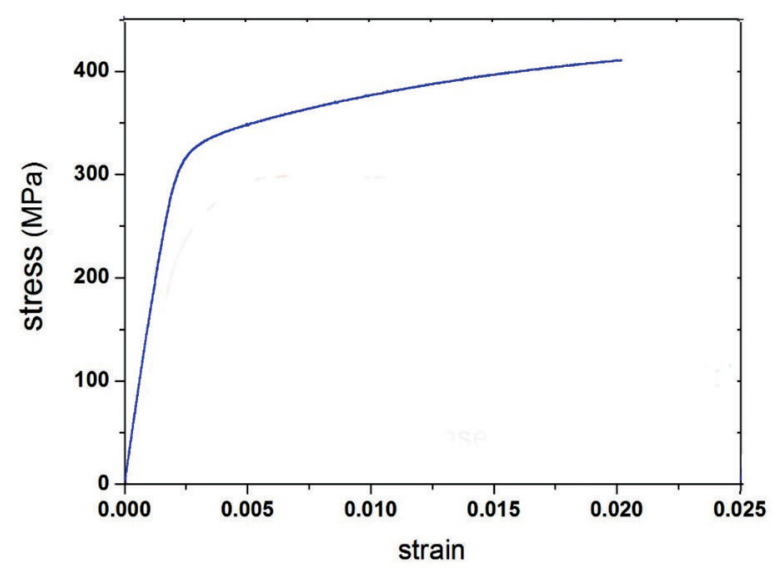

Fig. 3: The stress-strain response of defect-free material under monotonic tensile loading

The chemical compositions (wt.\%) of QT400-18 are shown in Table 1, and the tensile properties requirements and modulus of elasticity of the defect-free material are listed in Table 2. 
Figure 4 shows the shrinkage porosity exposed on the gauge surface of several specimens. The shrinkage porosity of each specimen exhibited various forms randomly. The designed specimen reflected the random distribution characteristics of porosity defect. An auxiliary wire-frame was used to mark the entire region of porosity defect (the dimension unit in the figure was millimeter ( $\mathrm{mm}$ ), and the specimen number was also marked).
Table 1: Chemical compositions of tested specimen (wt.\%)

$\begin{array}{cccccccc}\mathbf{C} & \mathbf{S i} & \mathbf{M n} & \mathbf{P} & \mathbf{S} & \mathbf{N i} & \mathbf{M g} & \mathrm{Fe} \\ 3.61 & 2.18 & 0.23 & 0.014 & 0.009 & 0.088 & 0.041 & \text { Bal. }\end{array}$

Table 2: Tensile properties requirements and modulus of elasticity of defect-free specimen

$\begin{array}{cccc}\begin{array}{c}\mathbf{0} .2 \% \text { yield } \\ \text { stress (MPa) }\end{array} & \begin{array}{c}\text { Ultimate } \\ \text { strength (MPa) }\end{array} & \begin{array}{c}\text { Reduction } \\ \text { of area (\%) }\end{array} & \begin{array}{c}\text { Modulus of } \\ \text { elasticity (GPa) }\end{array} \\ 320 & 400 & 18 & 167\end{array}$

\subsection{Fatigue test}

In engineering application, cast components always have to suffer alternating loading. During the operation of the diesel engine, cyclic tensile-tensile stress is one of the important load cases for the diesel block. The object of the experiments was to compare the fatigue life of iron castings with various levels of shrinkage porosity, so all fatigue tests were performed under a constant sinusoidal amplitude loading at room temperature. The tests were carried out on the Instron- 8802 servo hydraulic universal machine. To simulate the load at the high stress region on the diesel machine and estimate the low-cycle fatigue life, the maximum stress related to the harmonic load is set as $50 \%$ of the ultimate strength of the material. The maximal
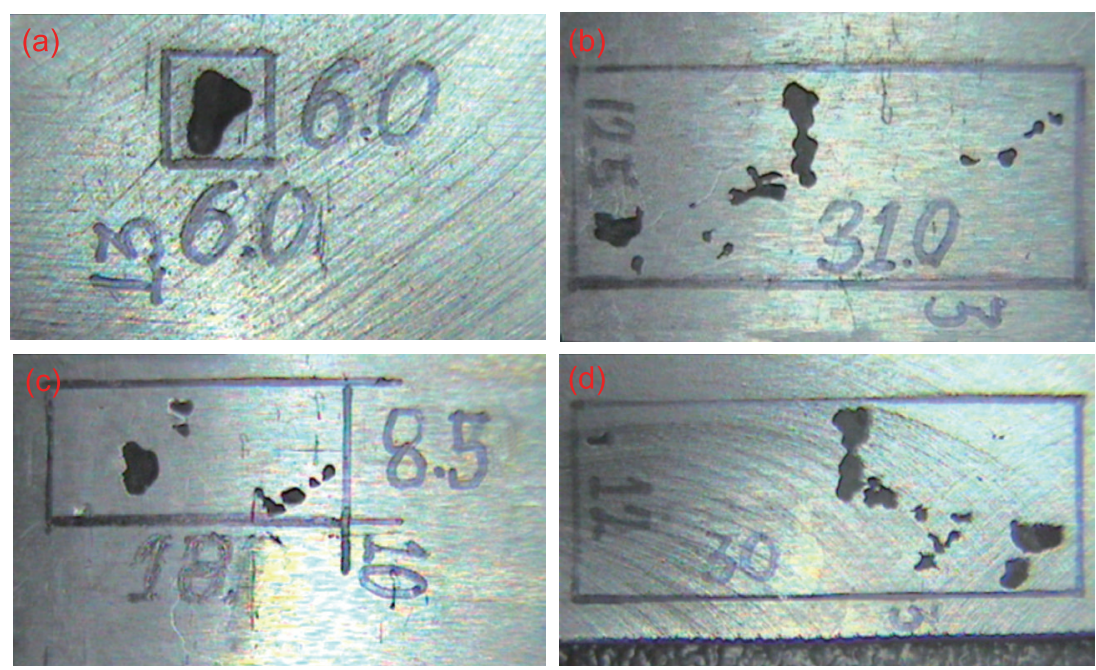

Fig. 4: Shrinkage porosity exposed on gauge surface of several specimens $(\mathrm{mm})$ stress applied in the test was $200 \mathrm{MPa}$ (The

loading case was proposed by the samples supplier: CSIC No.12 Research Institute). The stress ratio was 0.06 , that was $\sigma_{\min }$ l $\sigma_{\max }=0.06$. The alternating frequency of fatigue loading was 5 $\mathrm{Hz}$. The life (the cycle number until fracture) of each specimen was recorded using the MTS test system.

In addition, the influences of shrinkage porosity on the crack nucleation and propagation behaviors were studied using a scanning electron microscope (SEM). The shrinkage porosity area on the fracture surface (SPAFS) and alternating stress intensity factor (ASIF) were applied to quantify the relationship between shrinkage porosity and residual life.

\section{Results}

\subsection{Representation of shrinkage porosity}

In the fatigue tests, fracture occurred at the defect site for all samples which had various porosity levels. The shrinkage defect formed when the feed metal was not available to compensate for metal shrinkage caused by solidification. Compared with the base material (QT400-18), the microstructure of the defect region was discrete. Therefore, the porosity decreased the effective area available to support the external loading. Additionally, the small pores of shrinkage porosity were easy to generate stress concentration, so the fracture surface with shrinkage porosity was a critical cross-section.

The fracture surfaces of all samples were examined using a scanning electron microscope (SEM). In order to characterize the extent of shrinkage porosity, a variable (shrinkage percentage $\varphi)$ was defined. It was the area percentage of the shrinkage porosity, that is $\varphi=A_{\mathrm{d}} / A_{\mathrm{t}}$, where $A_{\mathrm{t}}$ was the area of fracture surface, and $A_{\mathrm{d}}$ was the shrinkage porosity area on the fracture surface (SPAFS), as shown in Fig. 5(a). For better distinction, the shrinkage porosity part on the fracture surface was marked in black using image analysis software [Fig. 5 (b)].

\subsection{Fatigue life results}

The fatigue life results of specimens with different levels of shrinkage porosity (shrinkage percentage) are listed in Table 3 . For all of the specimens, the shrinkage porosity area on

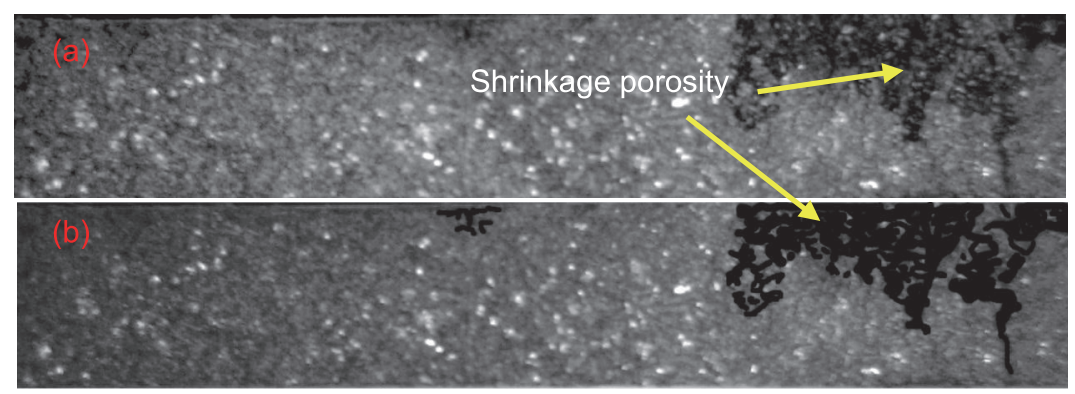

Fig. 5: Shrinkage porosity area on fracture surface (SPAFS) 
the fracture surface (SPAFS) ranged from $9.4 \mathrm{~mm}^{2}$ to 109.6 $\mathrm{mm}^{2}$, and their corresponding percentages were from $0.67 \%$ to $5.91 \%$. The test results showed that the life distribution varied greatly, the order magnitude of life ranged from $10^{3}$ to $10^{6}$. The general trend was that the life decreased with an increase in the porosity percentage, but the relationship was non-linear. Fatigue behavior was very sensitive to the material's microstructure and particularly porous defects; the residual life of a defect material dropped sharply even though a few percent of shrinkage porosity existed.

\section{Discussion}

\subsection{Fatigue fracture analysis}

In order to investigate the influence of shrinkage porosity on the fatigue crack initiation and propagation, the fracture surface was carefully observed using SEM. The macro- and micro-morphologies of shrinkage porosity region are shown in Fig. 6. It can be seen that a certain amount of visible porosity defects with irregular shape distribute randomly on the fracture surface [Fig. 6(a)], and the defects present dark-color, like some petty dinas in the base material. Figure 6(b) displays a microstructure of the shrinkage porosity region. The defect contains discontinuous dendrites and eutectic clusters, which are the reasons for stress concentration at the defect sites. These dendrites and eutectic clusters gather randomly and form pores

Table 3: SPAFS, shrinkage percentage, ASIF and fatigue life of test specimens

\begin{tabular}{|c|c|c|c|c|}
\hline $\begin{array}{c}\text { No. of } \\
\text { specimen }\end{array}$ & $\begin{array}{c}\text { SPAFS } \\
A_{d}\left(\mathrm{~mm}^{2}\right)\end{array}$ & $\begin{array}{c}\text { Shrinkage } \\
\text { percentage } \\
\varphi(\%)\end{array}$ & $\begin{array}{c}\text { ASIF } \Delta K_{I} \\
(\mathrm{MPa} \sqrt{\mathrm{mm}})\end{array}$ & $\begin{array}{c}\text { Fatigue life } \\
N \text { (Cycle) }\end{array}$ \\
\hline 1 & 23.7 & 2.75 & 367.8 & 564,700 \\
\hline 2 & 9.3 & 1.72 & 291.2 & 654,500 \\
\hline 3 & 69.8 & 4.71 & 481.5 & 10,700 \\
\hline 4 & 66.2 & 4.59 & 475.2 & 5,700 \\
\hline 5 & 5.8 & 1.36 & 259.05 & $1,408,700$ \\
\hline 6 & 10.2 & 1.80 & 297.4 & 982,500 \\
\hline 7 & 7.8 & 1.58 & 278.7 & $1,129,600$ \\
\hline 8 & 10.4 & 1.82 & 299.4 & 822,900 \\
\hline 9 & 18.6 & 2.44 & 346.2 & 962,000 \\
\hline 10 & 47.7 & 3.89 & 437.8 & 13,400 \\
\hline 11 & 39.9 & 3.56 & 418.7 & 14,400 \\
\hline 12 & 109.6 & 5.91 & 539.15 & 7,700 \\
\hline 13 & 101.3 & 5.68 & 528.5 & 12,700 \\
\hline 14 & 36.4 & 3.40 & 409.25 & 46,600 \\
\hline 15 & 21.4 & 2.61 & 358.55 & 147,300 \\
\hline 16 & 15.1 & 2.19 & 328.65 & 243,300 \\
\hline 17 & 13.6 & 2.08 & 320.15 & 521,421 \\
\hline 18 & 24.2 & 2.78 & 369.55 & 2,907 \\
\hline 19 & 23.7 & 2.74 & 367.45 & 427,151 \\
\hline 20 & 24.7 & 2.80 & 367.8 & 55,586 \\
\hline 21 & 9.4 & 0.67 & 475.2 & 360,553 \\
\hline 22 & 44.5 & 3.76 & 259.05 & 7,916 \\
\hline 23 & 21.7 & 2.63 & 297.4 & 212,809 \\
\hline
\end{tabular}
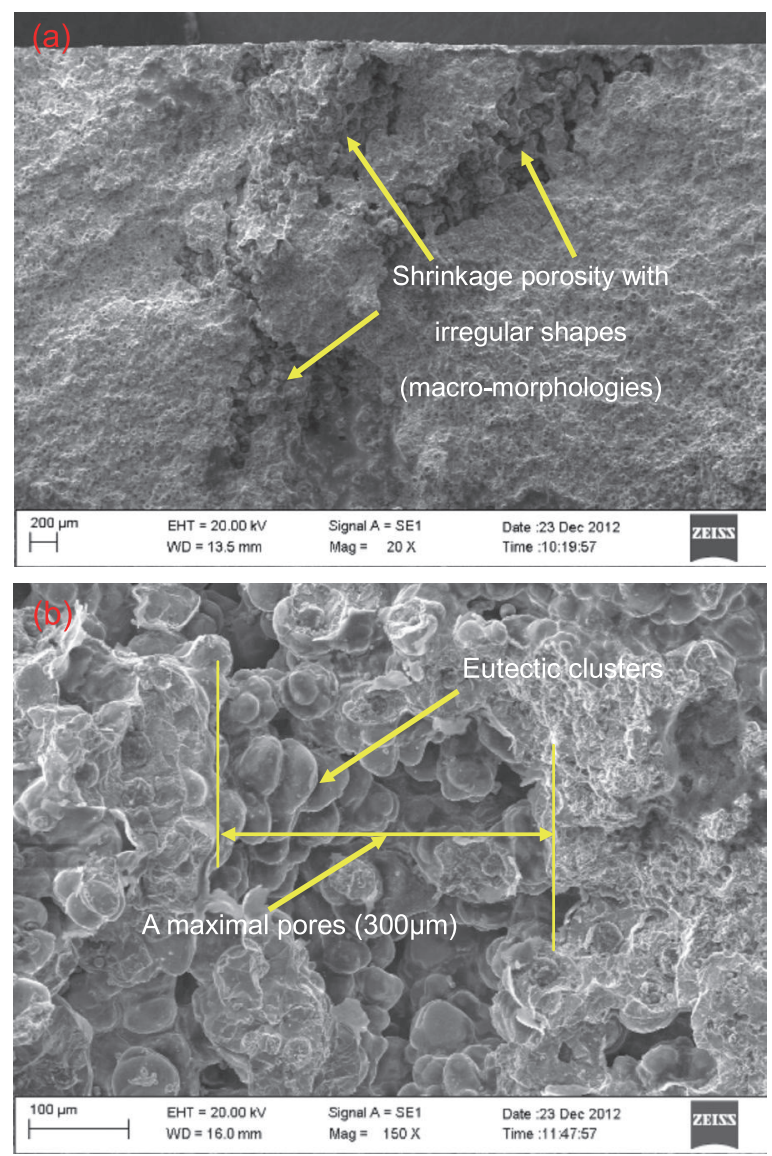

Fig. 6: Macro- and micro-morphologies of shrinkage porosity on fracture surface

or gaps, the maximal diameter of pores is $300 \mu \mathrm{m}$.

Figure 7 shows the fatigue stripes of the shrinkage porosity region. The slip process in shrinkage porosity region is not as orderly as the ordinary continuous medium; the slip bands are not unique, and their locations are more dispersed. Fatigue cracks propagate along different directions under alternating loading, and the lengths of slip bands are relatively short (Fig. 7 ( $a$ and $b$ ), the micro-morphology of porosity pores interfere with the fatigue sliding or hindering process greatly. In the shrinkage porosity region, the crack propagation path exhibits a great uncertainty, such as deviation, interruption, acceleration or deceleration ${ }^{[14,16]}$ This phenomenon may be related to the difference of the "crystal cohesion force" for shrinkage porosity. The difference is caused by the randomness distribution of porosity. Obviously, the morphology of shrinkage porosity affects the fatigue performance dramatically.

Figure 7 (b) and (c) show the morphology of crack nucleation; the crack usually nucleates from the discontinuous regions of crystalline, such as pit, pore or gap, the discontinuity is also introduced by inclusions in casting. A certain amount of micro cracks randomly distribute in the shrinkage porosity region, as shown in Figure 7 (c), and discontinuous gaps are also composed of these micro cracks. Smaller curvature radiuses of gap tips will be the points where it is easier to introduce stress concentration. Additionally, the shrinkage porosity with larger area or long and thin gaps will be easier to develop into a crack 

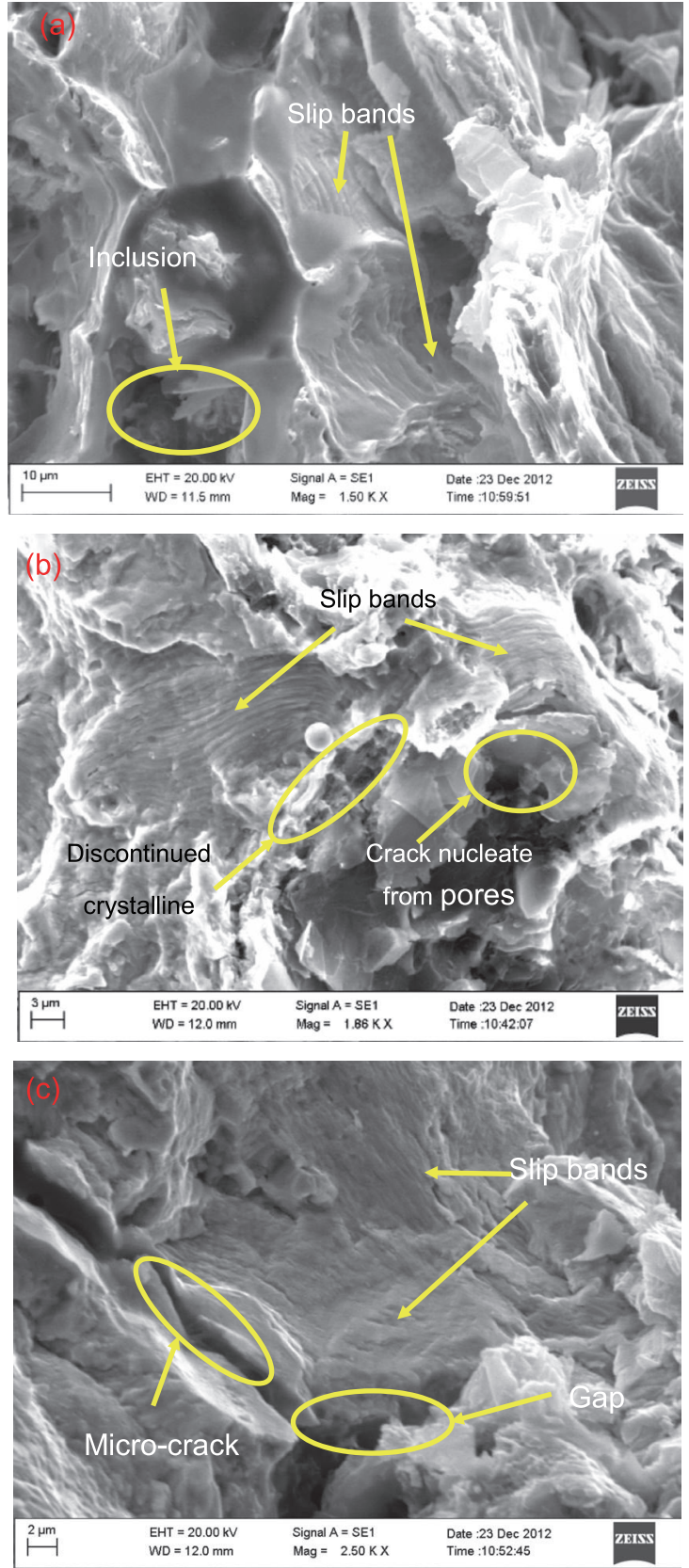

Fig. 7: Crack source and fatigue striation of shrinkage porosity region (Inter-granular discontinuous, micro cracks were the main influencing factors for fatigue behavior)

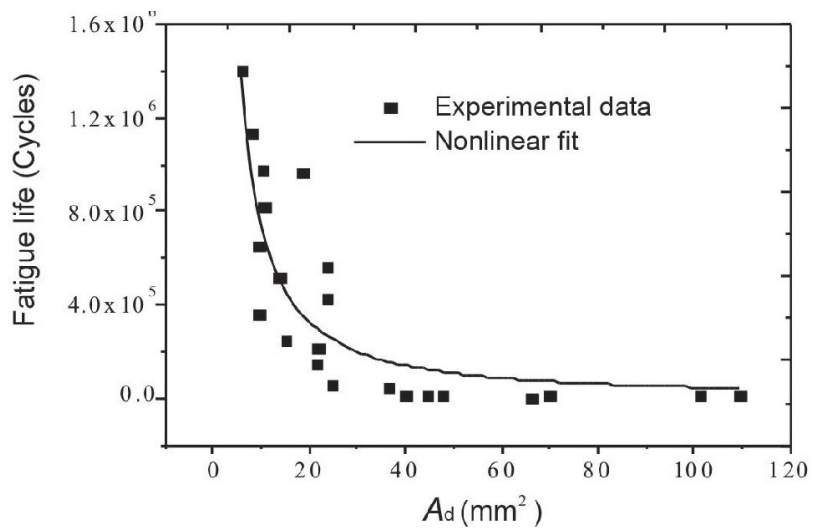

Fig. 8: The fitted curve between SPAFS and fatigue life nucleation source which provides more convenient paths for crack propagation because of lower fracture energy ${ }^{[14]}$, or the coalescence between micro cracks. The micro cracks lead to accelerated failure.

In summary, heterogeneity and local-randomness are the special characteristics of shrinkage porosity. The existence of the defects would be easier to develop into a crack nucleation source, and the primary factors of crack nucleation and propagation for shrinkage porosity are as follows: inter-granular discontinuous, micro cracks, and inclusions. The fatigue performance of castings with shrinkage porosity lies on the comprehensive influence of these factors.

\subsection{Fatigue life and SPAFS}

The shape, area, morphology, and the percentage of shrinkage porosity of different positions are varying, so the fatigue life of castings with shrinkage porosity is difficult to evaluate simply from the defect's morphology. In order to analyze the relationship between porosity defect and fatigue life, the level of shrinkage porosity was characterized by the shrinkage porosity area on the fracture surface $A_{\mathrm{d}}$.

The tested results for the fatigue life of all test specimens with various porosity degrees are plotted in Fig. 8. On the whole, the life decreases with an increase in SPAFS. The life curve declines sharply at the initial stage, which indicates that the fatigue performance is sensitive to shrinkage porosity, even a presence of low-level porosity will reduce the life dramatically.

A quantitative formula was established to evaluate the life distribution of the materials with shrinkage porosity. Using the nonlinear fitting method, the relationship between the fatigue life and SPAFS was described by a negative exponential function, as follows:

$$
N=1.154 \times A_{d}^{-1.195} \times 10^{7}
$$

where $N$ is the fatigue life (cycles) and $A_{\mathrm{d}}$ is the SPAFS $\left(\mathrm{mm}^{2}\right)$.

\subsection{Fatigue life and ASIF}

At the microscopic scale, the shrinkage porosity is a set of micro pores with different sizes. In the macroscopic view, these micro pores migrate into some arbitrary shapes. The shape, area, maximal pores, position, density etc. of different shrinkage porosity defects are various. Therefore, it is insufficient to use one single variable to describe the non-homogeneous and localrandom characteristics.

The fatigue performance depends mainly on the changing stress field caused by defects. In fracture mechanics, the stress intensity factor (SIF), $K$, is used to predict the stress state near the tip of a crack. The magnitude of SIF depends on sample geometry, the size and location of the crack, and the alternating stress intensity factor (ASIF) controls the crack propagation process. Therefore, ASIF reflects the comprehensive influence of multiple factors for defects, and can be used as a variable to evaluate the fatigue life of structure with shrinkage porosity defects ${ }^{[11]}$.

Murakami ${ }^{[11]}$ proposed an ASIF formula for material containing defects: 


$$
\Delta K_{\mathrm{I}}=\left(\sigma_{\max }-\sigma_{\min }\right) \times \alpha \times \sqrt{\pi \sqrt{A_{d}}}
$$

where $\sigma_{\max }$ is the maximal stress, $\sigma_{\min }$ is the minimal stress, $\alpha$ is a position coefficient, and $A_{\mathrm{d}}$ was the SPAFS. When the defects are exposed on the surface of casting, the value of $\alpha$ is suggested as 0.65 ; when the defects are hidden inside the casting, $\alpha$ is suggested as 0.5 .

According to the definition of ASIF by formula (2), the values of ASIF for all tested specimens were calculated and are listed in Table 3. The relationship between ASIF and fatigue life was plotted in Fig. 9, and a quantitative equation was fitted:

$$
N=4.8 \times\left(\Delta K_{\mathrm{I}}\right)^{-4.48} \times 10^{17}
$$

where $N$ is the fatigue life (cycles), $\triangle K_{\mathrm{I}}$ is the ASIF of shrinkage porosity defects (unit: $\mathrm{MPa} \sqrt{\mathrm{mm}}$ ). Compared with the SPAFS method, the dispersion of the above model is smaller. The relationship between the fatigue life and ASIF complied with a negative exponential function.

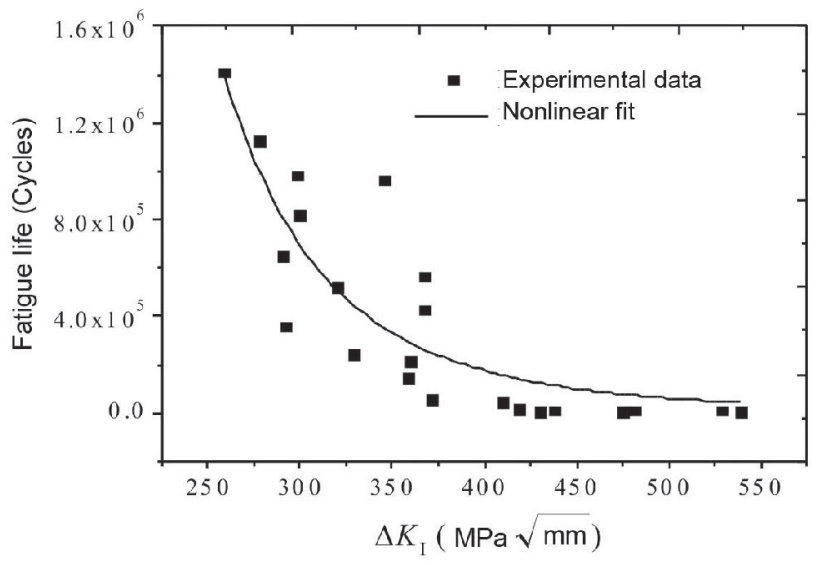

Fig. 9: Fitted curve between ASIF and fatigue life

\subsection{Equivalent initial crack method}

In engineering, crack propagation is often assumed to dominate fatigue life, and the residual life of material is often predicted by crack propagation analysis ${ }^{[12,15]}$. It would be more direct, if shrinkage porosity were treated as a crack, but there are some differences in the morphology and loading conditions. The ASIF also reflects the degree of alternating stress field near the defects; therefore, based on the intermediate variable of ASIF, the relationship between the shrinkage porosity and equivalent initial crack can be established. The fatigue life of material containing shrinkage porosity defects is equivalent to the crack propagation life of materials containing an initial crack.

In this present study, the comprehensive effect of SPAFS was assumed equivalent to an initial crack with a length of $\alpha_{i}$, that is to say, the stress intensity factor (SIF) caused by the shrinkage porosity and the initial crack were the same. The ASIF of an initial crack with a length of $\alpha_{\mathrm{i}}$ is as follows:

$$
K_{\mathrm{I}(i)}=Y \sigma \sqrt{\pi a_{i}}
$$

where $Y$ is the shape correction factor of specimen and $\sigma$ is the applied stress.

The crack propagation speed $\mathrm{d} a / \mathrm{d} N$ is usually defined by the Paris model. The crack length grows from $\alpha_{\mathrm{i}}$ to $\alpha_{\mathrm{i}+1}$ after one cycle. Correspondingly, the value of SIF will increase to $K_{\mathrm{I}(i+1)}$ from $K_{\mathrm{I}(i)}$, and the ASIF is $\Delta K_{i}=K_{\mathrm{I}(i+1)}-\mathrm{K}_{\mathrm{I}(i)}$, this is the ASIF based on variation of crack length. The relationship between the magnitude of crack propagation and ASIF can be derived by differential operation for equation (4):

$$
\mathrm{d} a=\frac{2 K_{\mathrm{I}}}{\pi Y \sigma^{2}} \mathrm{~d} K_{\mathrm{I}}
$$

Substituting equation (5) into the Paris model, the crack propagation rate can be expressed by SIF:

$$
\frac{\mathrm{d} K_{\mathrm{I}}}{\mathrm{d} N}=\frac{1}{2} \pi C Y^{2} \sigma^{2} K_{\mathrm{I}}^{(m-1)}
$$

where $C, m$ are the material parameters for crack propagation, their values can be determined by the crack growth experiment of the QT400-18 material ${ }^{[24]}$.

During fatigue process, the length of crack increases to the critical length $a_{\mathrm{c}}$ from an initial length of $a_{0}$, the SIF increases to its critical value $K_{\mathrm{IC}}$ from $K_{\mathrm{I} 0}$ correspondingly, and the final fatigue fracture will occur. The cycle number of the above process can be obtained by an integral operation of the Paris model:

$$
N=\int_{K_{\mathrm{I} 0}}^{K_{\mathrm{I}}} \frac{2 K_{\mathrm{I}}^{(1-m)}}{\pi Y^{2} C \sigma^{2}} \mathrm{~d} K_{I}=\frac{2\left[K_{\mathrm{IC}}^{(1-m)}-K_{\mathrm{I} 0}^{(1-m)}\right]}{\pi Y^{2} C(2-m) \sigma^{2}}
$$

Under alternating stress with a stress ratio of $R$, the ASIF is $\Delta K_{\mathrm{I}}=(1-R) K_{\mathrm{Imax}}$, and correspondingly, the failure criteria is $\Delta \mathrm{K}_{\mathrm{IC}}=(1-\mathrm{R}) \mathrm{K}_{\mathrm{IC}}$. Equation (7) can be rewritten as:

$$
N=\int_{(1-R) K_{\mathrm{I} 0}}^{(1-R) K_{\mathrm{IC}}} \frac{2\left[(1-R) K_{\mathrm{I}}\right]^{(1-m)}}{\pi Y^{2} C \sigma^{2}} \mathrm{~d} K_{\mathrm{I}}
$$

Equation (8) is the life prediction model for the porosity defect casting based on the method of equivalent initial crack. The fatigue life predicted by equation (8) and experimental data are plotted in Fig. 10.

\section{Conclusions}

The following conclusions can be drawn from the study of QT400-18 iron with shrinkage porosity.

(1) Shrinkage porosity reduces the life of QT400-18 sharply. When the shrinkage percentage ranges from $0.67 \%$ to $5.91 \%$, the order of magnitude of corresponding life scatter varies from $10^{3}$ to $10^{6}$. The general trend is that the life is decreased with the increase in porosity percentage, but their relationship is nonlinear.

(2) The micro-morphology of shrinkage porosity interferes 


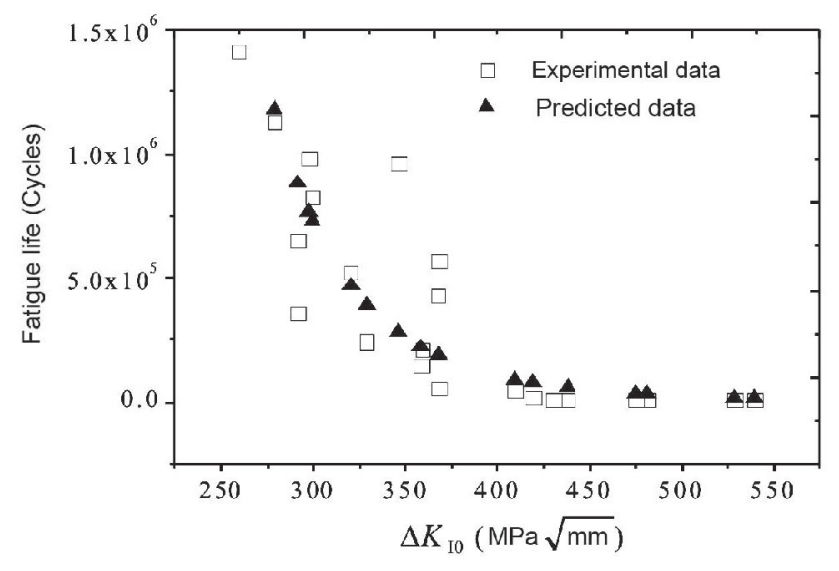

Fig.10: Comparison between life prediction and experimental data

with the fatigue sliding or hindering process. The slip process in shrinkage porosity region is not as orderly as the ordinary continuous medium, the slip bands are not unique and their locations are dispersive. The locations of inter-granular discontinuous, micro cracks, inclusions are easier to develop into crack nucleation sources.

(3) The SPAFS and ASIF of shrinkage porosity can be used to evaluate the tendency of life distribution. Their tendency formulas are described by the negative exponential functions. Based on the internal variable of ASIF, shrinkage porosity can be equivalent to an initial crack. The life of shrinkage porosity defect material can be predicted by the crack propagation life of material containing an initial crack. The method is helpful in determining a probable lifespan in engineering application.

\section{References}

[1] Monroe R. Porosity in Castings. AFS Transactions, 2005: 1-28.

[2] Tijani $Y$, Heinrietz A, Atets $W$, et al. Detection and influence of shrinkage pores and non-metallic inclusions on fatigue life of cast aluminum alloys. Materials Properties, Characterization, and Modeling, 2012 (2): 225-232.

[3] Wang Zehua, Zhao Weihua, Zhou Zehua, et al. Effect of shrinkage porosity on mechanical porosities of ferritic ductile iron. China Foundry, 2013, 10(3): 141-147. (In Chinese)

[4] Zhao Weihua, Zhou Zehua, Yu Xiaode, et al. Effect of shrinkage porosity on mechanical properties of QT400-18L casting. Physical Testing and Chemical Analysis (Part A: Physical Testing), 2011, 47: 546-549. (In Chinese)

[5] Wang Fang, Zhao Haidong, Zhang Kewu, et al. Relationship between mechanical properties and porosity in ADC12 die casting. Special Casting\& Nonferrous Alloys, 2008, 28(03): 204207. (In Chinese)

[6] Hu Bo, Xiong Shoumei, Masayuki Murakami, et al. Relationship between porosity distribution and mechanical properties of vacuum die casting AM50 magnesium alloy. Foundry, 2009, 58(11): 1115-1128. (In Chinese)

[7] Hardin R A and Beckermann C. Effect of porosity on deformation, damage, and fracture of cast steel. Metallurgical and Materials
Transactions A: Physical Metallurgy and Materials Science, 2013, 44(12): 5316-5322.

[8] Wan Qian, Zhao Haidong, and Ge Jilong. Effect of microporosities on fatigue behavior of aluminum die castings. The Chinese Journal of Nonferrous Metals, 2015, 25(3): 568-574. (In Chinese)

[9] Gao Y X, Yi J Z, Lee P D, et al. The effect of porosity on the fatigue life of cast aluminium-silicon alloys. Fatigue \& Fracture of Engineering of Materials \& Structures, 2004, 27(7): 559-570.

[10] Avalle M, Belingardi G, Cavatorta M P, et al. Casting defects and fatigue strength of a die cast aluminium alloy: a comparison between standard specimens and production components. International Journal of Fatigue, 2002, 24: 1-9.

[11] Wang Q G, Apelian D, and Lados D A. Fatigue behavior of A356-T6 aluminum cast alloys - Part I. Effect of casting defects. Journal of Light Metals, 2001, 1: 73-84.

[12] Mayer H, Papakyriacou M, Zettl B, et al. Influence of porosity on the fatigue limit of die cast magnesium and aluminum alloys. International Journal of Fatigue, 2003, 25: 245-256.

[13] Nadot $Y$, Mendez J, and Ranganathan N. Influence of casting defects on the fatigue limit of nodular cast iron. International Journal of Fatigue, 2004, 26: 311-319.

[14] Deegan P T, Stephens R I, Hardin R A, et al. The effect of porosity on the fatigue life of 8630 cast steel. AFS Transaction, 2007: 80-92.

[15] Boivin P. Anisotropy, cracking, and shrinkage of vertisol samples: Experimental study and shrinkage modeling. Geoderma, 2007, 138(1): 25-38.

[16] Kim K S, Park J C, Yim C D, et al. Effect of porosity on high cycle fatigue behavior of casing AM60B magnesium alloy. Procedia Engineering, 2011, 10: 165-170.

[17] Collini L, Pirondi A, Bianchi R, et al. Influence of casting defects on fatigue crack initiation and fatigue limit of ductile cast iron. Procedia Engineering, 2011, 10: 2898-2903.

[18] Cao X B, Zhao J, Fan J H, et al. Influence of casting defects on fatigue behavior of A356 aluminum alloy. International Journal of Cast Metals Research, 2014, 27(6): 362-368.

[19] Mo D F, He G Q, Hu Z F, et al. Crack initiation and propagation of cast A356 aluminum alloy under multi-axial cyclic loading. International Journal of Fatigue, 2008, 30: 1843-1850.

[20] Xu Zhiqiang, Zhang Xinliang, Wen Wei, et al. Effect of pore position in depth on stress concentration around pore on sample surface. Journal of Yansan University, 2012, 36(4): 293-297. (In Chinese)

[21] Cai Rentao, He Guoqiu, Jiang Xiaosong, et al. Study on factors of fatigue life of A319 cast aluminum alloy by grey relation analysis. Metallic Functional Material, 2011, 18(3): 55-58. (In Chinese)

[22] Murakami Y. Metal fatigue: effects of small defects and nonmetallic inclusions. Elsevier Science Ltd., Oxford, 2002, Charpter 2:18.

[23] Costa N, Machado N, Silva F S. A new method for prediction of nodular cast iron fatigue limit. International Journal of Fatigue, 2010, 32: 988-995.

[24] Zhao Junfeng, Liu Wei, Wang Hui, et al. Reliability analysis of fatigue crack growth life of QT400-18. Mechanical Science and Technology for Aerospace Engineering, 2015, 34(6): 940-944. (In Chinese) 